\title{
AflSte20 Regulates Morphogenesis, Stress Response, and Aflatoxin Biosynthesis of Aspergillus flavus
}

\author{
Ding Li, Ling Qin, Yinchun Wang, Qingchen Xie, Na Li, Shihua Wang * and Jun Yuan *
}

Key Laboratory of Pathogenic Fungi and Mycotoxins of Fujian Province, Key Laboratory of Biopesticide and Chemical Biology of Education Ministry, and School of Life Sciences, Fujian Agriculture and Forestry University, Fuzhou 350002, China; echoliding@fafu.edu.cn (D.L.); lingqin@fafu.edu.cn (L.Q.);

Annewangyinchun@fafu.edu.cn (Y.W.); qingchenxie9@m.fafu.edu.cn (Q.X.); lina3180515023@fafu.edu.cn (N.L.)

* Correspondence: wshmail@m.fafu.edu.cn (S.W.); yjmail2008@fafu.edu.cn (J.Y.);

Tel./Fax: +86-591-8378-7126 (S.W.)

Received: 13 November 2019; Accepted: 11 December 2019; Published: 13 December 2019

\begin{abstract}
Various signaling pathways in filamentous fungi help cells receive and respond to environmental information. Previous studies have shown that the mitogen-activated protein kinase (MAPK) pathway is phosphorylation-dependent and activated by different kinase proteins. Serine/threonine kinase plays a very important role in the MAPK pathway. In this study, we selected the serine/threonine kinase AflSte20 in Aspergillus flavus for functional study. By constructing Aflste20 knockout mutants and complemented strains, it was proven that the Aflste20 knockout mutant $(\triangle A f l s t e 20)$ showed a significant decrease in growth, sporogenesis, sclerotinogenesis, virulence, and infection compared to the WT (wild type) and complemented strain $\left(\triangle A\right.$ flste $\left.20^{C}\right)$. Further research indicated that $\triangle A$ flste 20 has more sensitivity characteristics than WT and $\triangle A$ flste $20^{C}$ under various stimuli such as osmotic stress and other types of environmental stresses. Above all, our study showed that the mitogen-activated kinase AflSte20 plays an important role in the growth, conidia production, stress response and sclerotia formation, as well as aflatoxin biosynthesis, in A. flavus.
\end{abstract}

Keywords: aflatoxin; Aspergillus flavus; HOG pathway; Aflste20

Key Contribution: MAPK Aflste20 gene was identified in A. flavus and had effects in sclerotia, virulence, aflatoxin biosynthesis, and response to osmotic stress.

\section{Introduction}

Aspergillus flavus is a common saprophytic aerobic fungus. It belongs to the family of Aspergillaceae in the phylum of Ascomycota and is mainly distributed in the warm temperate zone [1]. A. flavus is not only a common pathogen of plants but also a human pathogen, and long-term exposure to $A$. flavus or more than 20 other Aspergillus species in humans and animals can induce asthma, exogenous alveoli, and allergic bronchial aspergillosis [2-4]. During the growth, transportation, and storage of crops, A. flavus can induce various crop diseases like ear rot in corn, aflaroot in peanuts, and boll rot in cotton [5]. Food safety issues caused by A. flavus are due to its representative secondary metabolites: aflatoxins (AFT), cyclopiazonic acid (CPA), and aflatrem, et al. [1,6-8]. Aflatoxin, as a highly toxic fungal toxin with very stable physical and chemical properties, was classified as a first-grade carcinogen by the World Health Organization's (WHO) international agency for research on cancer in 1993 [9]. Therefore, the signal pathways that affect the regulation of virulence-related factors need to be further explored in A. flavus.

Mitogen-activated protein (MAP) kinases are a kind of ubiquitous protein kinases in eukaryotes. The mitogen-activated protein kinase (MAPKs) cascade is regulated by phosphorylation, and its 
signaling pathway is necessary for cells to adapt to environmental changes [10,11]. In yeast, for example, MAPKs can simultaneously differentiate cellular immune responses and mediate intracellular cascades. Three signal transduction elements, MAPKKK, MAPKK, and MAPK, function sequentially in the kinase cascade [12]. When the cells are stimulated by different environmental factors, the corresponding MAPK cascade is activated. MAPKKK leads to phosphorylation of MAPKK followed by rapid phosphorylation of MAPK by MAPKK $[10,13]$. In MAPK cascades, the high-osmolarity glycerol (HOG) pathway responding to osmotic stress has caught large attention for a long time. In yeast, the HOG pathway is activated by two different upstream branches, SLN1 and SHO1. Branch SLN1 relies on a two-component system of Sln1, Ypd1, and Ssk1 that activate downstream Ssk2/Ssk22 MAPKKKs. Sho1, Ste20, and Ste11 are required in the Sho1 branch of the HOG pathway to transmit osmotic stress signals. The two branches converge at Pbs2 [13-16].

In eukaryotes such as fungi, protein kinases play an important role in cell signal transduction [17]. In the budding yeast Saccharomyces cerevisiae, Ste20 as a kinase plays a role in the MAPK pathway [18]. It has been found to involve in cell differentiation, growth, mitosis, and apoptosis. In addition, Ste20 participates in MAPK signaling cascades as a response to osmotic stress in A. flavus [12]. Ste20 has an N-terminal Cdc42/Rac interactive binding domain (CRIB) and a protein kinase domain on its C-terminal [19]. Previous studies on fungi showed that Ste20 interacts with Cdc42 (small GTPase) and often participates in the cascade reaction of MAPK by phosphorylating Ste11, and regulates many cellular processes such as mycelia development, fungal toxicity, and osmotic stress [19-21].

Although the studies of Ste20 has been carried out in some species, the roles of Ste20 have not been clarified until now in A. flavus. In this study, we are interested in the role of Ste20 in the regulation of the biological functions of $A$. flavus, including in growth and development, $\mathrm{AFB}_{1}$ production, and its response to various environmental stresses. In order to explore the hypothetical role of Ste20 in these processes, the Aflste 20 knockout and complemented mutant strains were constructed. By analyzing the results of experiments, we found that AflSte20 played important roles in asexual development, sclerotia formation, virulence, secondary metabolism, and stress response in A. flavus.

\section{Results}

\subsection{Sequences Analysis of AflSte20 in A. flavus}

DNA and protein sequences of AflSte20, AFLA_035530, and XP_002375063.1. were obtained from National Center for Biotechnology Information Database (NCBI). AflSte20 was predicted to be a serine/threonine kinase protein with 848 amino acids. The phylogenetic tree was constructed by comparing the sequence of AflSte20 with the amino acid sequences of orthologs of other species, including $A$. oryzae, A. parasiticus, A. nomius, A. nidulans, A. heteromorphus, A. niger, A. fumigatus, A. steynii, Penicillium roqueforti, $S$. cerevisiae, Neurospora crassa and Candida albicans, which were retrieved from NCBI (http://www.ncbi.nlm.nih.gov). The evolutionary relationship of these proteins was analyzed by the software Molecular Evolutionary Genetic Analysis Version 7.0.26 (MEGA 7) (Figure 1A). Domains in Ste20 were further analyzed by using the software SMART and IBS 1.0 (Figure 1B). After domain analysis of AflSte20 protein, it was found that there were two domains, including CRIB_dom (Cdc42/Rac interactive binding motif domain) and Prot_kinase_dom (Protein Kinase domain). Compared to other homologous proteins, the CRIB_dom and Prot_kinase_dom were found to be highly conserved in the fungal species analyzed. 

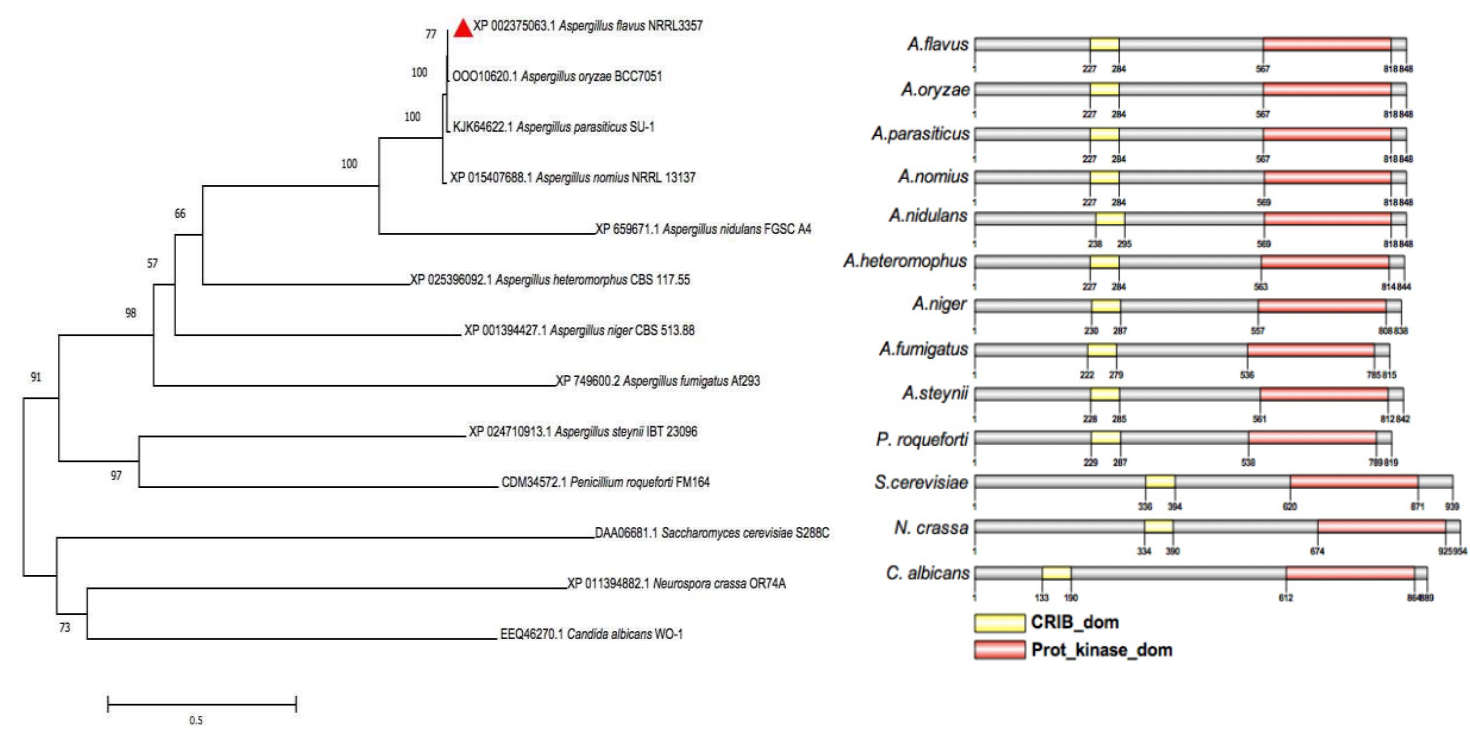

Figure 1. Bioinformatics analysis of the mitogen-activated protein kinase (MAPK) pathway kinase AflSte20 from 13 different fungi: A. flavus (XP 002375063.1), A. oryzae (OOO10620.1), A. parasiticus (KJK64622.1), A. nomius (XP_015407688.1), A. nidulans (XP_659671.1), A. heteromorphus (XP_025396092.1), A. niger (XP_001394427.1), A. fumigatus (XP_749600.2), A. steynii (XP_024710913.1), Penicillium roqueforti (CDM34572.1), S. cerevisiae (DAA06681.1), Neurospora crassa (XP_011394882.1) and Candida albicans (EEQ46270.1). (A) Phylogenetic relationship of Ste20 homologs from different species was analyzed by MEGA 7.0. Neighbor joining with a bootstrap of 1000 replicates was used to generate the phylogenetic tree. (B) Conserved domain analysis of the fungi AflSte20 proteins. InterPro (http: //www.ebi.ac.uk/interpro/scan.html) and IBS 1.0 were used in the analysis.

\subsection{AflSte20 is Involved in Vegetative Growth and Conidial Production}

In order to explore the influence of Aflste20 on A. flavus, the knockout mutant strain ( $\triangle A$ flste20) was constructed by a homologous recombination principle (Figure S1A). Whereas, in order to certify the role of Aflste 20 and to confirm that the phenotypic effects observed were exclusively due to the deletion of Aflste20, we created the Aflste20 complementation strain. PCR verification of the obtained strains showed that ORF (Open Reading Frame) could be detected in WT (wild type) and $\triangle A f l s t e 20^{C}$, but not in $\triangle$ Aflste20, while AP (the fusion PCR product by $5^{\prime}$ UTR of the Aflste20 gene and part of pyrG) and BP (the fusion PCR product by $3^{\prime} \mathrm{UTR}$ of the Aflste20 gene and part of $p y r G$ ) bands with the correct size could be detected in $\triangle A$ flste 20 and $\triangle A$ flste $20^{C}$ (Figure S1B), proving a successful generation of the knockout strain. RT-PCR and qRT-PCR tests further verified the expression of the Aflste20 transcript in the WT and complementation strain but not in the null mutant, confirming that the targeted gene had been deleted. (Figure S1C,D).

To verify the function of the Aflste20 gene in the growth process of A. flavus, WT, $\triangle$ Aflste20, and $\triangle$ Aflste $20^{C}$ strains were inoculated on potato dextrose agar (PDA) and Yeast Extract Sucrose (YES) media, then grown at $37^{\circ} \mathrm{C}$ for 4 days in the dark. The results showed that under the same culture conditions, the colony diameter of the $\Delta$ Aflste 20 mutant was restrained dramatically $(p<0.05$; $n=5$ ) compared to $\Delta$ Aflste 20 and WT strains. The growth inhibition rate of $\Delta$ Aflste 20 were $9.94 \%$ and $14.18 \%$ in YES and PDA media respectively. Under the microscope, the conidiophores of $\triangle A$ flste 20 were observed to be more sparsely distributed than that of WT and $\triangle A$ flste2 $0^{C}$ (Figure 2A,B). Also, the statistical results indicated that compared to WT $\left(5.52 \times 10^{7} / \mathrm{mL}\right)$ and $\triangle A f l s t e 20^{C}\left(5.66 \times 10^{7} / \mathrm{mL}\right)$ strains, the amount of conidia produced by the $\triangle A$ flste 20 mutant $\left(3.15 \times 10^{7} / \mathrm{mL}\right)$ were significantly decreased on PDA $(p<0.001 ; n=5)$ (Figure 2C). qRT-PCR analysis of brlA (a regulatory gene in primary regulation of asexual development) and $a b a A$ (an essential gene for both differentiation and function of 
phialides, and is activated by BrlA during the middle stages of conidiophores development $[22,23])$ genes showed that the relative expression of the $a b a A$ and brlA gene in $\triangle A f l s t e 20$ (abaA: $48.9 \%$; brlA: $32.3 \%$ ) was significantly $(p<0.001 ; n=5)$ lower than that of WT and $\triangle A f l s t e 20^{C}$ (Figure 2D). All the above results suggest that AflSte20 plays a positive regulatory role in the control of growth and asexual sporulation of $A$. flavus.

A

YES

PDA

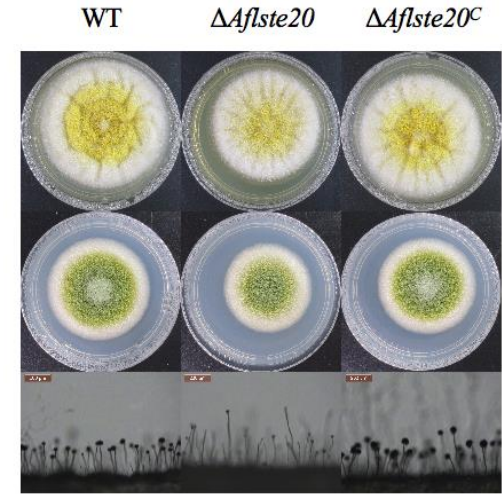

C

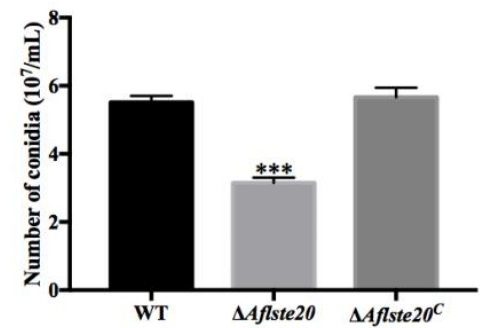

B
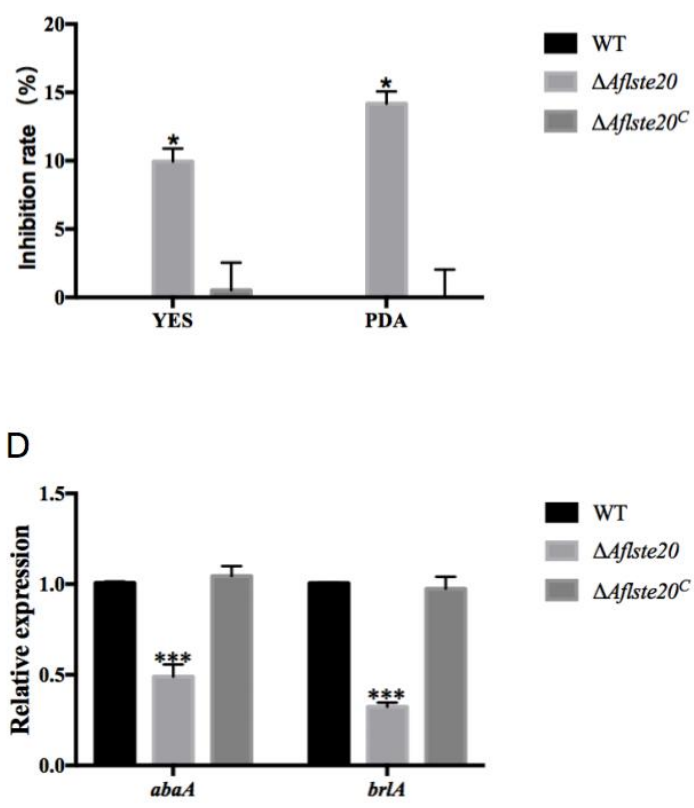

Figure 2. The function of AflSte20 in vegetative growth and conidial production in A. flavus. (A) The phenotype of wild type (WT), $\triangle A$ flste20, and $\triangle A$ flste $20^{C}$ strains. These strains were grown on YES/PDA medium at $37^{\circ} \mathrm{C}$ for $72 \mathrm{~h}$ and the conidiophores were observed under microscope (200×). (B) The growth inhibition rate of strains was calculated based on the result of (A), according to the formula: growth inhibition rate $=\left[\left(\right.\right.$ diameter of WT strains colony-diameter of $\triangle A$ flste 20 or $\triangle A$ Aflste $20^{C}$ strains colony/diameter of WT strains colony)] $\times 100$. (C) The conidia number of WT, $\triangle A$ flste20, and $\triangle A$ flste $20^{C}$ strains were calculated by hemocytometer. (D) The expression level of $a b a A$ and $b r l A$ genes in A. flavus by qRT-PCR analysis. For panels (B), (C), and (D), each bar indicates the mean \pm standard deviation (SD) of five replicate assay experiments. ${ }^{*}$ represents significant difference $(p<0.05),{ }^{* * *}$ represents significant difference $(p<0.001)$.

\subsection{AflSte20 Mediates Sclerotia Formation in A. flavus}

A. flavus relies on the production of sclerotia, which are considered to be the resistant structures that act as a repository for sexual spore and allow the fungi to survive in the adverse living environment [24]. To explore the influence of the Aflste20 gene on the production of sclerotia by A. flavus, $10^{4}$ asexual spores were inoculated on the Wickerham (WKM) medium and cultured in the dark for seven days. The number of sclerotia was counted after cleaning mycelia with $75 \%$ alcohol (Figure $3 \mathrm{~A}$ ). The results showed that the sclerotia production by $\triangle A f l s t e 20$ ( 0 per 5 plugs) was significantly impaired $(p<0.001$; $n=5$ ) compared to that of WT (195.2 per 5 plugs) and $\triangle A$ flste $20^{C}$ (205.6 per 5 plugs) strains (Figure 3B). qRT-PCR was carried out to check the expression level of $s c l R$ and $n s d C$ genes, which are the positive regulators of sclerotia formation [25]. And the results showed a downward trend in the knockout mutant $\triangle$ Aflste 20 strain of $s c l R(46.08 \%, p<0.01 ; n=5)$ and $n s d C(36.28 \%, p<0.001 ; n=5)$ (Figure 3C). All of these results suggest that AflSte20 positively regulates the sclerotia production in A. flavus. 
A

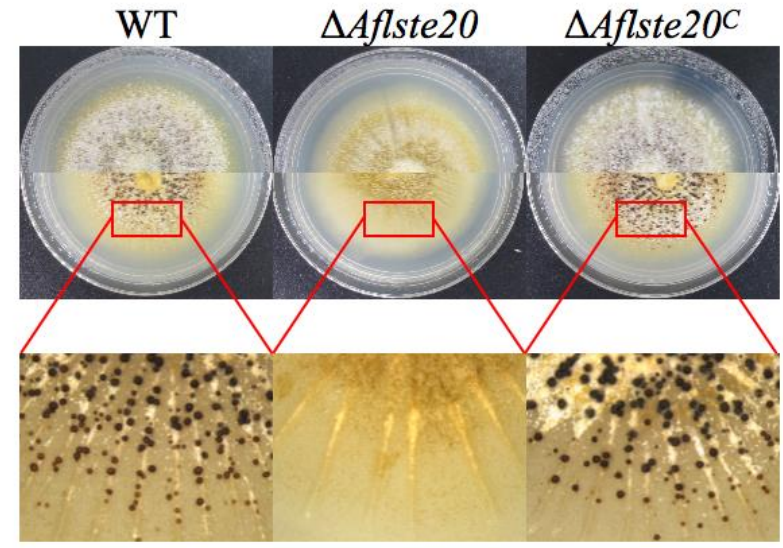

B

C
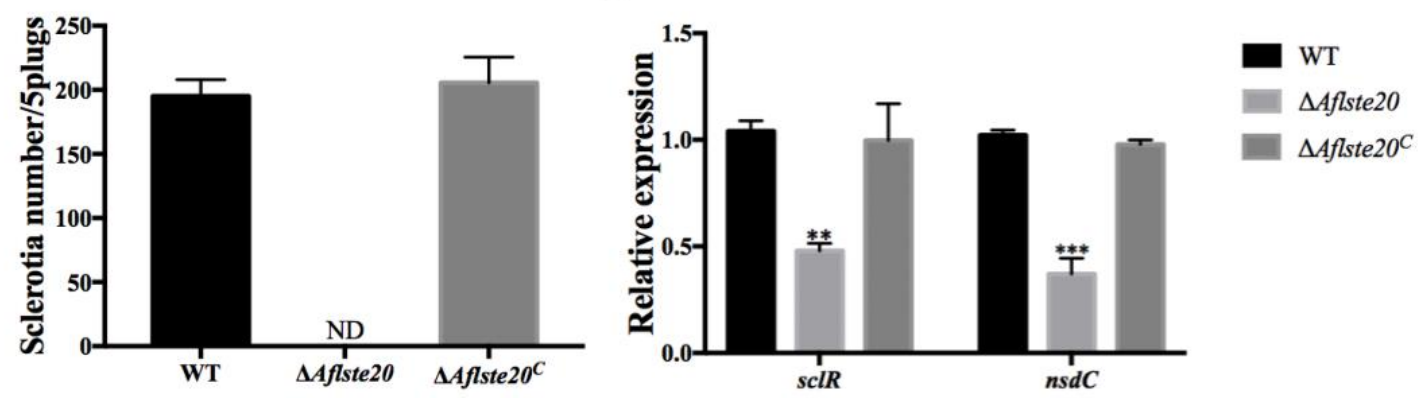

Figure 3. The role of Aflste20 in sclerotia formation in A.flavus. (A) Phenotypes of the WT, $\triangle A$ flste20, and $\triangle A$ flste $20^{C}$ strains were observed after grown on a WKM medium for 7 days in the dark. The mycelia were cleaned with $75 \%$ ethanol to make sclerotia visible. (B) The number of sclerotia from WT, $\triangle A$ flste 20 , and $\triangle$ Aflste $20^{C}$ strains. (C) The expression level of $s c l R$ and $n s d C$ genes in A. flavus by qRT-PCR analysis. For panels (B) and (C), each bar indicates the mean \pm standard deviation (SD) of three replicate assay experiments. ${ }^{* *}$ represents significant difference $(p<0.01)$, and ${ }^{* * *}$ represents significant difference $(p<0.001)$.

\subsection{AflSte20 Participates in the Response to Different Stresses in A. flavus}

Previous studies elaborated that the ste20 gene is involved in MAPK pathway in yeast [12]. Due to a predicted role of AflSte20 in signal transduction previously [26], we analyzed whether Aflste20 takes part in the response to a variety of environmental stress conditions such as hyperosmotic pressure, oxidation stress, and cell wall damage. In this study, first we analyzed the effect of AflSte20 under osmotic stress. We found that, in the presence of osmotic stress induced by $1 \mathrm{M} \mathrm{NaCl}$ or $99 \%$ water activity, the growth was significantly inhibited compared to the WT and complementation strains $(p<0.001 ; n=5)$, indicated that $\Delta$ Aflste 20 mutant was more sensitive to osmotic stress (Figure $4 \mathrm{~A}, \mathrm{~B})$. Subsequently, the expression level of HSP and GRE genes which are related with osmolality were determined, the result indicated that the expression levels of the HSP and GRE genes were significantly $(p<0.001 ; n=5)$ decreased to $59.05 \%$ and $76.70 \%$, respectively, in $\triangle$ Aflste 20 (Figure 4 C). Similarly, the $\triangle$ Aflste 20 mutant also showed a higher inhibition rate which was about $253 \%$ of the wild type under oxidative stress with $0.01 \%$ t-BooH [(CAS number: $75-91-2)(p<0.01 ; n=5)$ ], $166 \%$ and $189 \%$ of the wild type under cell wall integrity damage with $100 \mu \mathrm{g} / \mathrm{mL}$ lauryl sodium sulfate (SDS) $(p<0.001 ; n=5)$ and with $200 \mu \mathrm{g} / \mathrm{mL}$ calcofuor white (CFW) $(p<0.05 ; n=5)$, respectively (Figure $4 \mathrm{D}$,E). Overall, these results suggest that $\Delta$ Aflste 20 does not only participate in the response of $A$. flavus to hyperosmotic stress, but also to oxidation stress and cell wall stress. 
A YES

$1 \mathrm{M} \mathrm{NaCl}$

99\%Aw

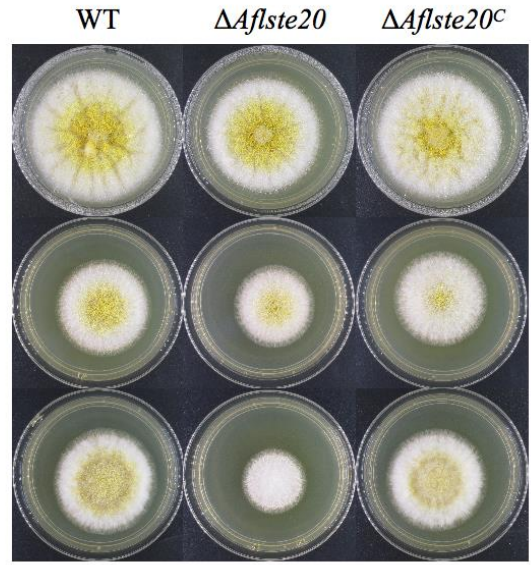

D

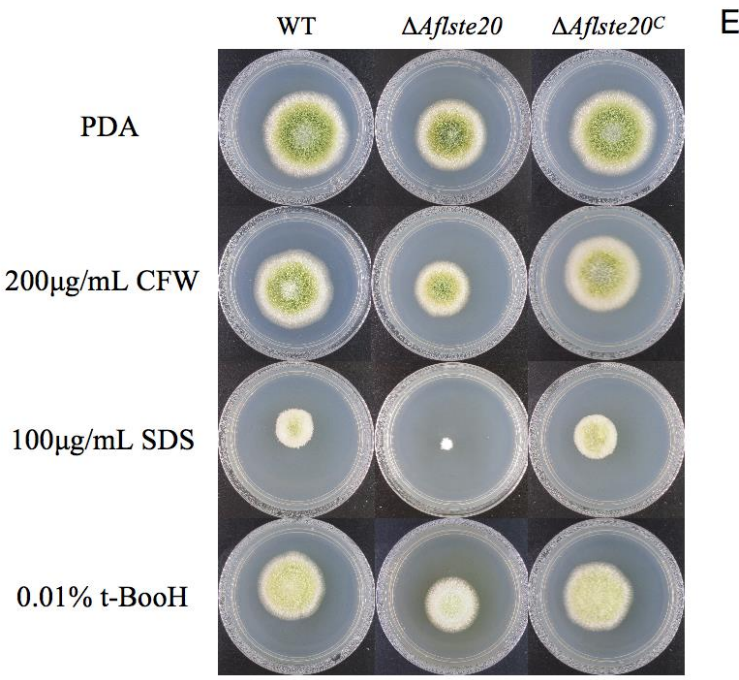

B

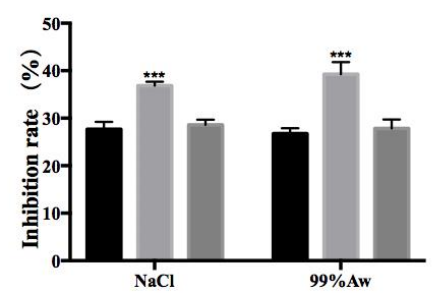

WT

- $\triangle$ Aflste20

$\triangle A$ afste20 ${ }^{C}$

C
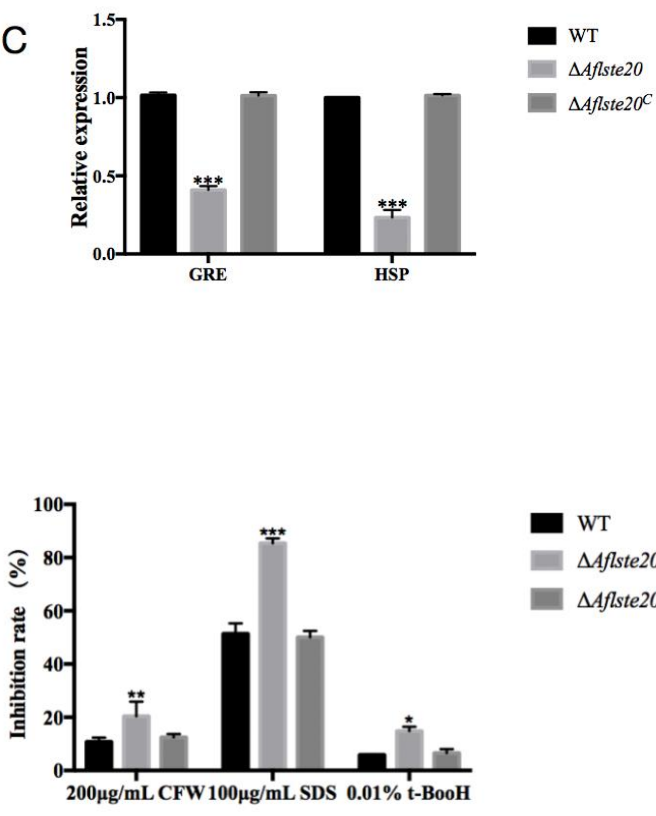

WT

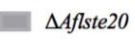

$\triangle$ Aflste20

Figure 4. Phenotype and inhibition rate of strains under different stress conditions. (A) Morphology of WT, $\triangle$ Aflste20, and $\Delta$ Aflste $20^{C}$ strains under hyperosmotic stress. (B) The inhibition of osmotic stress on the mycelium growth of each strain. (C) qRT-PCR analysis of expression level of the genes (HSP and GRE) related with osmolality. (D) The colony of each strain under cell wall stress and oxidation stress. (E) The mycelial growth inhibition of all strains under cell wall stress and oxidation stress. For panels (B), (C), and (E), each bar indicates the mean \pm standard deviation (SD) of five replicate assay experiments. * refers to significant difference $(p<0.05),{ }^{* *}$ represents significant difference $(p<0.01)$, and ${ }^{* * *}$ represents significant difference $(p<0.001)$.

\subsection{AflSte20 Positively Regulates Aflatoxin Biosynthesis}

In order to evaluate whether AflSte20 plays a function in the regulation of aflatoxin biosynthesis. $\mathrm{AFB}_{1}$ was extracted from WT, $\triangle$ Aflste20, and $\triangle A$ Afste $20^{C}$ strains in the YES liquid medium after incubation for 6 days at $29^{\circ} \mathrm{C}$ and detected by TLC (Thin Layer Chromatograph) (Figure 5A). According to the TLC result, the $\mathrm{AFB}_{1}$ production of $\triangle A$ Afste 20 strains was decreased more than one half when compared with WT strains $(p<0.001 ; n=5)$ (Figure 5B). Simultaneously, the expression of regulatory genes, aflR and aflS, and key structural genes including aflD, aflK, and aflQ in the aflatoxin biosynthesis cluster, were severely repressed in the $\triangle$ Aflste 20 mutant strain (aflD: $56.53 \%$; aflK: $28.42 \%$; aflQ: $42.10 \%$; aflR: $37.63 \%$; aflS: $18.38 \%$ ) (Figure 5C). All the above results confirmed that AflSte20 could positively regulate $\mathrm{AFB}_{1}$ production in $A$. flavus. 


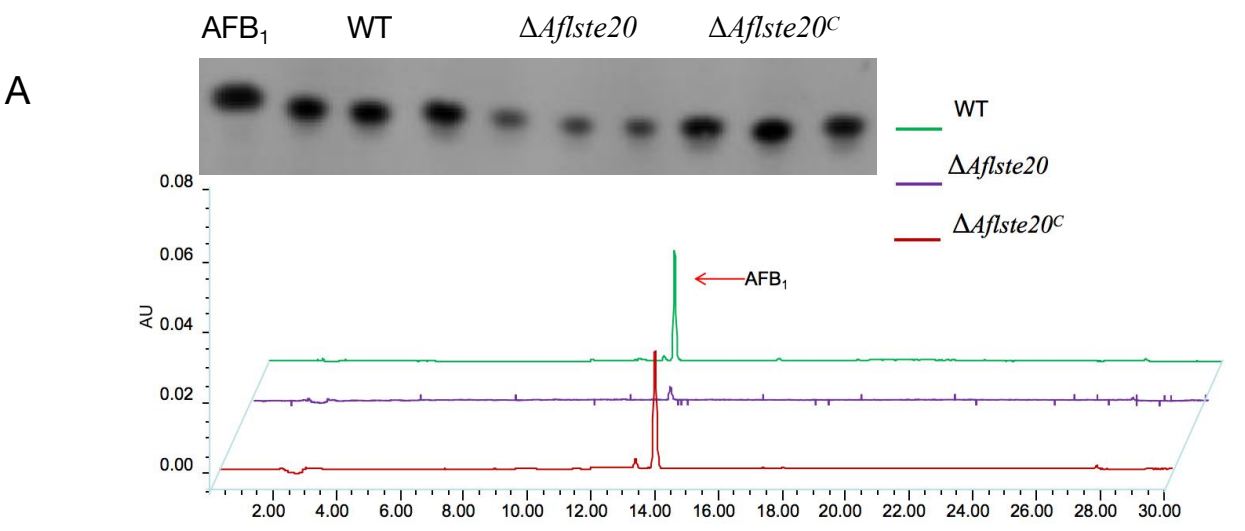

B

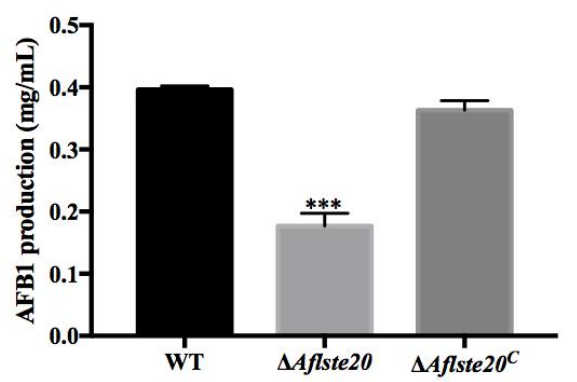

C

Time/min

Figure 5. Role of Aflste20 in aflatoxin biosynthesis. (A) thin-layer chromatography (TLC) and highperformance liquid chromatography (HPLC) analysis of $\mathrm{AFB}_{1}$ production in WT, $\triangle$ Aflste20, and $\triangle A$ flste $20^{C}$ strains after 7 days of incubation. (B) Relative $\mathrm{AFB}_{1}$ production was calculated from (A). (C) The qRT-PCR analysis of the expression of key structure genes (aflD, aflK, aflQ, aflR, and aflS) in A. flavus. Bars in panels (B) and (C) indicate the mean \pm standard deviation (SD) of assays performed three times. ${ }^{* *}$ represents significant difference $(p<0.01)$, and ${ }^{* * *}$ represents significant difference $(p<0.001)$.

\subsection{AflSte20 Has an Influence on Conidiation and Aflatoxin Biosynthesis to Crop Seeds}

As a common pathogenic fungus, A. flavus is particularly harmful to crops. To explore the effect of AflSte20 in A. flavus on the conidial production and aflatoxin biosynthesis in the infection process, the seeds of crops were infected with $\triangle A$ flste20, WT, and $\Delta A$ flste $20^{C}$ strains and grown in dark for seven days (Figure $6 \mathrm{~A}$ ). The ability of different strains to produce asexual spores and $\mathrm{AFB}_{1}$ during infection was determined (Figure 6A,C). According to the experimental results, we found that the spore production of $\triangle A f l s t e 20$ strains infection were significantly decreased to about $44.31 \%$ (peanut) and $35.27 \%$ (maize) when compared to WT $(p<0.001 ; n=5)$. We also found the $\mathrm{AFB}_{1}$ production of $\Delta$ Aflste20 strains after infection was significantly reduced to about $50.00 \%$ (peanut, $p<0.01 ; n=5$ ) and $32.50 \%$ (maize, $p<0.001 ; n=5$ ) of the wild type (Figure $6 \mathrm{~B}-\mathrm{D}$ ). The results demonstrated that the ability of $A$. flavus to infect crops decreased significantly when the Aflste 20 gene was absent. All of these results indicate that the Aflste 20 gene was important for $A$. flavus to maintain its ability for asexual spore production and aflatoxin biosynthesis when infecting crop seeds such as peanuts and maize. 

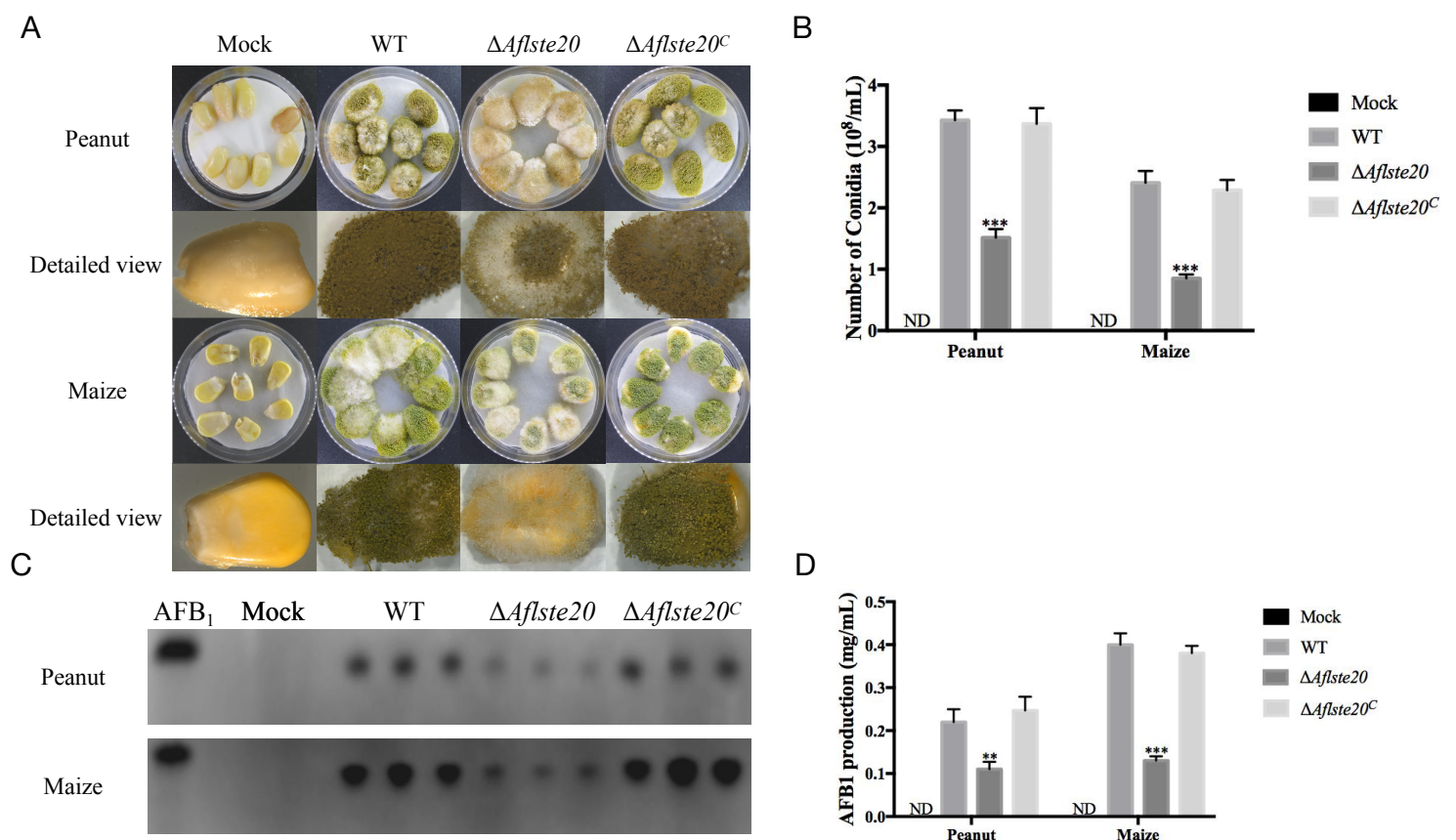

Figure 6. The effect of Aflste20 deletion on conidiation and aflatoxin biosynthesis to crops. (A) The peanut and maize kernels were inoculated with WT, $\triangle A$ flste 20 , and $\Delta A f l s t e 20^{C}$ strains. (B) Conidia production of infected peanut and maize seeds. (C) Aflatoxin was analyzed by TLC, which was extracted from infected peanut and maize kernel seeds. (D) The relative $\mathrm{AFB}_{1}$ production was analyzed from $(C)$. For panels B and D, each bar indicates the mean \pm standard deviation (SD) of assays performed three times. ${ }^{* *}$ represents significant difference $(p<0.01)$, and ${ }^{* * *}$ represents significant difference $(p<0.001)$.

\section{Discussion}

Previous studies found that the MAPK pathway plays an important role in eukaryotes, and that the cascade of MAPK is involved in apoptosis, growth regulation, hyperosmosis regulation, cell tolerance, gene expression, cell division, and ascospore development [11]. As a member of the protein kinase family, the yeast p21-activated protein kinase(PAK) homolog Ste20 is essential for the Sho1-dependent activation of the Hog1 MAP kinase in response to severe osmotic stress, and this function of Ste20 in the HOG pathway requires binding of the small GTPase Cdc42 $[27,28]$, but until now, no study on Ste20 homologues in A. flavus had been reported. In this study, we found that the Aflste20 gene consists of 2544 nucleotide residues. The comparison of amino acid sequences with other selected orthologues revealed that AflSte20 in A. flavus showed the lowest identity (46.18\%) to S. cerevisiae, and had the highest identity $(99.76 \%$ ) to A. oryzae (Figure 1). A protein kinase domain in the C-terminal of AflSte20 was highly conserved between AflSte20 and its orthologues. In recent studies, Ste20 orthologues have been increasingly reported to play important roles in different fungi. In yeast, the activated Ste20 can bind with the SH3 domain of Sho1 to promote the activation of Hog1 [29], and it also participates in the mycelium growth, colony reproduction, and other life activities [27]. In this study, we investigated the effects of AflSte20 mutations on the fungal biology and aflatoxin biosynthesis of A. flavus. Firstly, we found that the $\Delta A f l s t e 20$ strain was significantly inhibited in vegetative growth, and conidiation occurred independently of the culture used or the surface of crops. Our results suggested that AflSte20 might play an important regulatory role in the growth and asexual reproduction in A. flavus. On the other hand, some fungi produce sclerotium, a sexual reproductive and survival structure, to adapt to adverse environmental conditions [30]. Besides impacting the function of growth and development, the Aflste 20 deletion mutant also exhibited observable effects on sclerotia production. Compared to WT and $\triangle A f l s t e 20^{C}$, our results showed that sclerotia production was almost blocked in the Aflste 20 deletion mutant. Simultaneously, we also found that the expression of the sexual development-related 
genes, $s c l R$ and $n s d C$, were prominently suppressed in the $\Delta A f l s t e 20$. Thus, for the first time, the result demonstrates that AflSte20 positively regulates sexual reproduction and would be a key factor to make fungi survive under stress conditions in A. flavus. Together, these results suggested that AflSte20 could control, directly or indirectly, both asexual and sexual developmental cycles. Compared to the media used, we found that if there were enough carbon sources in the environment, AflSte20 involved in the asexual reproduction and activated BrlA and AbaA. On the contrary, with carbon starvation, AflSte20 also works but activated sexual development which induced the production of sclerotia. Thus, the role of AflSte20 in the asexual and sexual developmental cycles might depend on the outside ambient and overlap in the carbon starvation pathway. To resolve this confusion, further research is urgently needed.

MAPK cascades have been found in different fungi, such as Fusarium spp., Aspergillus spp., M. oryzae, B. cinerea, and so on. In A. nidulans, two MAPK pathways (Hog1-MAPK and Slt2-MAPK) have been found to be involved in many external environmental stresses such as osmotic pressure and cell wall stress [31-35]. In the present study, we found that AflSte20 could play vital functions in responses to hyperosmotic stress and positively correlated with mycelia development. Our findings were reliable based on the previous study on yeast which showed that ste20 gene in the HOG pathway plays an essential role in response to osmotic stress [12]. Studies on Candida glabrata revealed that Ste20 is necessary in response to osmotic stress and maintains a complete cell wall integrity pathway [36]. Thus, we were also interested in whether AflSte20 would respond to cell wall stress in A. flavus. As expected, consistent with the effect of Ste20 in C. glabrata, the loss of Aflste 20 also leads to the increased sensitivity to cell wall stress in A. flavus. Furthermore, in S. cerevisiae, when the protein on HOG pathway is absent, it is found that the mutant strain is more sensitive to oxidative stress [37]. We also wondered whether AflSte20 has a crosstalk with other pathways and plays a role in responding to oxidative stress. In fact, as AflSte20 performed various metabolic processes, the highly reduced tolerance of the $\Delta$ Aflste20 strain supports that AflSte20 might play an important role in the response to oxidative stress and functioning when oxidative damage occurs. One possible explanation for this phenomenon is that AflSte20, which works in the HOG pathway, has a crosstalk with an intact cell wall integrity pathway or other signaling pathways related to oxidative stress. An alternative possibility is that AflSte20, with a regulatory CRIB domain on the $\mathrm{N}$ terminal, facilitates the kinase to interact directly with all kinds of signaling molecules and regulatory proteins [38].

In the pathogenic fungus C. albicans, Cla4 is a protein in the Ste20p family, and this protein deficiency results in reduced toxicity and also inhibits the toxicity of C. albicans in the mouse model [39]. It is also worth mentioning that although the Ste20 has caught great attention for a long time, the comprehension about its pathogenic function in A. flavus is still a puzzle. So, we focused on the aflatoxin production and infection ability of AflSte20 to crops. $\mathrm{AFB}_{1}$, as a secondary metabolite of A. flavus, is a key factor correlated with the resistance to reactive oxygen species (ROS) during infection and enhancing its virulence on plants [40,41]. A significant decrease of $\mathrm{AFB}_{1}$ with reduced infection ability of $\Delta$ Aflste 20 to crops suggests that at least one of the reasons affecting the virulence of $A$. flavus is due to the Aflste20 gene which can regulate the key genes in the aflatoxin biosynthesis-relevant cluster (Figure 6C).

In summary, our experiments demonstrated that AflSte20 is involved in many physiological activities such as the growth and development of A. flavus, the production of secondary metabolites and crop contamination of $A$. flavus, and plays an important role in resisting many external stresses such as hyperosmosis stress. Above all, this work may provide ideas and references for the prevention and control of $A$. flavus pollution.

\section{Materials and Methods}

\subsection{Strains and Culture Conditions}

All strains used in this study were given in Table 1. All strains were cultivated on potato dextrose agar (PDA, BD Difco, USA), YES medium and WKM agar medium at $37^{\circ} \mathrm{C}$ or $29^{\circ} \mathrm{C}$ for growth assay 
and sclerotia assay. Each strain was cultivated on five plates, and all experiments were repeated three times.

Table 1. Strains used in the study.

\begin{tabular}{ccc}
\hline Strains & Genotype Description & Source \\
\hline A. flavus CA14 & $\Delta k u 70, \Delta p y r G$ & Purchased from FGSC \\
wild-type (WT) & $\Delta k u 70, \Delta p y r G::$ AfpyrG & This study \\
$\Delta$ Aflste20 & $\Delta k u 70, \Delta p y r G::$ AfpyrG, $\Delta$ Aflste20 & This study \\
$\Delta$ Aflste20 & $\Delta k u 70, \Delta$ Aflste20::Aflste20, $\Delta p y r G::$ AfpyrG & This study \\
\hline
\end{tabular}

\subsection{Bioinformatics Analysis}

Gene sequence (Accession number AFLA_035530) and protein sequence (ID XP_002375063.1) of Aflste20 were downloaded from NCBI (http://www.ncbi.nlm.nih.gov). The phylogenetic tree was created by MEGA 7 with different protein sequences of other Ste20 orthologs downloaded from NCBI. The domains of these proteins were analyzed with InterPro (http://www.ebi.ac.uk/interpro/scan.html) and edited with IBS 1.0.

\subsection{Gene Deletion and Complementation}

The homologous recombination method was used to obtain the deletion mutant $\triangle A f l s t e 20$ [42]. Three fragments (1194 bp 5'-UTR of Aflste20, 1038 bp 3'-UTR of Aflste20 and 1890 bp pyrG gene) were amplified and then connected by overlap PCR. The fragments were then transferred into the protoplasts of $A$. flavus CA14. For the complemented strains [42], firstly, the ste20 fragment in A. flavus was amplified with ste20-C-p1/ste20-C-p4 primers, then transferred into the $\Delta$ Aflste20 protoplasts with $2 \mathrm{mg} / \mathrm{mL}$ 5-FOA (5-fluoroorotic acid) to substitute $p y r G$ in $\triangle A f l s t e 20$. Lastly, the $p y r G$ gene was inserted behind the ste20 to get the pyrG prototroph complemented strains $\left(\triangle A f l s t e 20^{C}\right)$ via a homologous recombination. The complemented strain was confirmed by PCR. With an actin gene as the inner reference, both of the verified $\Delta$ Aflste 20 mutant and $\triangle A f l s t e 20^{C}$ strains were also verified by qRT-PCR assay. The primers used in the study are listed in Tables 2 and 3.

Table 2. Primers used for the construction of strains in this study.

\begin{tabular}{|c|c|c|}
\hline Primer Name & Sequence $\left(5^{\prime}-3^{\prime}\right)$ & Amplified Fragment \\
\hline ste $20-p 1$ & TGCTTAGAGGATGGGATT & \multirow{2}{*}{ 5’UTR of Aflste 20} \\
\hline ste20-p3 & GGGTGAAGAGCATTGTTTGAGGCCGCTAGGCTCAGTGATGG & \\
\hline ste20-p6 & GCATCAGTGCСTCСТСTCAGACCCAGATACCCATTGCTCC & \multirow{2}{*}{ 3'UTR of Aflste20 } \\
\hline ste $20-p 8$ & CACCAGCCCACATAGAAT & \\
\hline ste20-p4 & GCСТCАAАСАATGСТСТTСАССС & \multirow{2}{*}{ A. fumigatus pyrG } \\
\hline ste20-p5 & GTCTGAGAGGAGGCACTGATGC & \\
\hline ste20-p2 & TTTGGCACTCGCTTGTCC & \multirow{2}{*}{ Fusion PCR } \\
\hline ste $20-p 7$ & CCGCTCAAGTCTGGGTTA & \\
\hline ste20-p9 & TCGGTTAATCACATCTGTCTC & \multirow{2}{*}{ ORF validates primers } \\
\hline ste20-p10 & CATCAATCATCGCCATCTA & \\
\hline pyrG-801 & CAGGAGTTCTCGGGTTGTCG & $\mathrm{AP}$ \\
\hline pyrG-1020 & CAGAGTATGCGGCAAGTCA & $\mathrm{BP}$ \\
\hline ste $20-C-p 1$ & GCTTCTGGTGGCGTATT & \multirow{2}{*}{$5^{\prime} \mathrm{UTR}$ of $\triangle$ Aflste $20^{C}$} \\
\hline ste $20-C-p 2$ & GGGTGAAGAGCATTGTTTGAGGCCGCTCAAGTCTGGGTTAT & \\
\hline ste20-C-p3 & GCATCAGTGCCTCCTCTCAGACCTGATGTCTCGCCTGTTA & \multirow{2}{*}{$3^{\prime} \mathrm{UTR}$ of $\triangle$ Aflste $20^{C}$} \\
\hline ste $20-C-p 4$ & CTCCGCCGCAACTTTAT & \\
\hline ste $20-C-p 5$ & CTCTGGGTGGTGATGGA & \multirow{2}{*}{ Fusion PCR } \\
\hline ste20-C-p6 & AGAATACGAGGCTTGTGG & \\
\hline
\end{tabular}

\subsection{Measurement of Conidia, Conidiophores, and Sclerotia}

In order to determine the quality and amount of conidia, conidiophores, and sclerotia, $10^{4}$ conidia were added to YES, PDA, and WKM solid media, respectively (10 mL media for one plate), and grown 
at $37^{\circ} \mathrm{C}$ in the dark. The colony diameter was measured after five days. Conidia were dispersed in $3 \mathrm{~mL}$ of $0.05 \%$ Tween-20 water solution, then the number of conidia were calculated by using a hemocytometer. For conidiophores investigation, the hyphae were scraped and cut as a rectangle with solid media by a surgical blade. Then these media with hyphae were added onto a glass slide and cultivated at $37^{\circ} \mathrm{C}$ overnight. Conidiophores were observed through a light microscope (Magnification scale, 200×). For sclerotia formations analysis, WKM solid medium was used to induce the production of sclerotia. WT, $\Delta$ Aflste 20 , and $\Delta$ Aflste $20^{C}$ strains $\left(10^{7}\right.$ spores $\left./ \mathrm{mL}\right)$ were incubated onto WKM media ( $1 \mu \mathrm{L}$ for one plate) at $37^{\circ} \mathrm{C}$ in the dark for seven days, and sclerotia were counted by the method described in detail by Yang et al. [43].

\subsection{Stress Assay}

To understand the role of Aflste20 gene response to multiple stress in A. flavus, the WT, $\Delta$ Aflste20, and $\triangle$ Aflste $20^{C}$ strains were cultured onto PDA agar medium at $37^{\circ} \mathrm{C}$ in the dark for 4 days with an oxidative stress agent $(0.01 \% \mathrm{t}-\mathrm{BooH})$, hyperosmotic stress agent $(1 \mathrm{M} \mathrm{NaCl}$ and $99 \%$ water activity), cell membrane stress agent $(100 \mu \mathrm{g} / \mathrm{mL}, \mathrm{SDS})$, and cell wall stress agent $(200 \mu \mathrm{g} / \mathrm{mL} \mathrm{CFW})$ obtained from Sigma-Aldrich, St. Louis., MO, USA. To determine the effect of Ste20 on the stress response of A. flavus, the relative growth inhibition rates were analyzed using the formula as followed: growth inhibition rate $=[$ (diameter of the colony without inhibitor-diameter of colony with inhibitor $) /$ diameter of colony without inhibitor] $x 100$. The assay was repeated at least three times.

\subsection{Determination of AFB1 Production}

For the thin-layer chromatography (TLC) analysis and high-performance liquid chromatography (HPLC) analysis of aflatoxins (AF) production, WT, $\triangle$ Aflste20, and $\Delta$ Aflste $20^{C}$ strains $\left(10^{7} \mathrm{spores} / \mathrm{mL}\right)$ were inoculated into $10 \mathrm{~mL}$ YES liquid media at $29^{\circ} \mathrm{C}$ in dark for seven days, $(30 \mu \mathrm{L}$ spore suspension per plate). After that, aflatoxin was extracted using a method previously described by Yang et al. [44]. The supernatant samples were analyzed by TLC with a solvent system (chloroform: acetone = 9:1) and detected by ultraviolet light. The quantity of the AF production was analyzed by the Gene Tools software. For HPLC analysis, extracted AF was detected by an HPLC system (Waters, Milford, MA, U.S.A.) on a MYCOTOX reversed-phase C18 column $(4.6 \times 250 \mathrm{~mm}$, Pickering Laboratories, USA) according to a method previously described [45].

\subsection{Conidiation and Aflatoxin Biosynthesis of A. flavus in Crop Seeds}

The method to detect asexual spore production and aflatoxin biosynthesis of $A$. flavus in crop seeds was performed according to the previously illustrated procedure by $\mathrm{Hu}$ et al. [42]. Briefly, the crop kernels were washed with $0.05 \%$ sodium hypochlorite (Shanghai Bojing Chemical Co.,Ltd., Shanghai, China) and the peanut and corn seeds were put into a suspension with $10^{5} \mathrm{spore} / \mathrm{mL}$ conidia of each strain in a rotary shaker at $80 \mathrm{r} / \mathrm{min}$ for $30 \mathrm{~min}$. Viable cotyledon was dried and laid on a sterile petri dish plate to cultivate at $29^{\circ} \mathrm{C}$ in dark for 7 days.

\subsection{Quantitative Real-Time Polymerase Chain Reaction (qRT-PCR)}

To determine the expression level of the genes related to different phenotypes. A. flavus WT, $\triangle$ Aflste20, and $\triangle$ Aflste $20^{C}$ strains were inoculated on YES medium and grown for $72 \mathrm{~h}$ at $37^{\circ} \mathrm{C}$ in the dark, then mycelium was collected. Total RNA was extracted from $0.1 \mathrm{~g}$ mycelium using an RNA isolation kit (Promega, Madison, WI, USA). And cDNA was synthesized using a First Strand cDNA Synthesis Kit (TransGen Biotech, Beijing, China). Then, as a template, cDNA was used for qRT-PCR amplification with SYBR Green qRT-PCR mix (TaKaRa Biotechnology, Japan) in a PikoReal Real-Time PCR system (Thermo Fisher Scientific, USA). The expression levels of target genes were calculated by the $2^{-\Delta \Delta C t}$ method [46]. All the primers used in this experiment were listed in Table 3 . All the experiments were performed three times. 
Table 3. Primers used for amplifying the related genes in this study.

\begin{tabular}{ccc}
\hline Gene & Forward Sequences $\mathbf{( 5}^{\prime} \mathbf{-} \mathbf{3}^{\prime} \mathbf{)}$ & Reverse Sequences $^{\left(\mathbf{5}^{\prime} \mathbf{-} \mathbf{3}^{\prime} \mathbf{)}\right.}$ \\
\hline Aflste20 & ATCAACGACTCGCACAATAA & GCTCGCCCTCAATCATCT \\
brlA & GCCTCCAGCGTCAACCTTC & TCTCTTCAAATGCTCTTGCCTC \\
$a b a A$ & TCTTCGGTTGATGGATGATTTC & CCGTTGGGAGGCTGGGT \\
$n s d C$ & GCCAGACTTGCCAATCAC & CATCCACCTTGCCCTTTA \\
$s c l R$ & CAATGAGCCTATGGGAGTGG & ATCTTCGCCCGAGTGGTT \\
aflR & AAAGCACCCTGTCTTCCCTAAC & GAAGAGGTGGGTCAGTGTTTGTAG \\
aflS & CGAGTCGCTCAGGCGCTCAA & GCTCAGACTGACCGCCGCTC \\
aflD & GTGGTGGTTGCCAATGCG & CTGAAACAGTAGGACGGGAGC \\
aflK & GAGCGACAGGAGTAACCGTAAG & CCGATTCCAGACACCATTAGCA \\
aflQ & GTCGCATATGCCCCGGTCGG & GGCAACCAGTCGGGTTCCGG \\
actin & ACGGTGTCGTCACAAACTGG & CGGTTGGACTTAGGGTTGATAG \\
GRE & GCGTATCGTCGTTACCTCATC & CCTTCTCCTTTACCTCCTCGAT \\
HSP & CCGGCATACTATGTCTCGTCT & TAGGGCCTTCGTCGAACA \\
\hline
\end{tabular}

\subsection{Statistical Analysis}

The data for all the experiments were expressed as means \pm standard deviation. At least three biological replicates were used for analysis. Tukey's multiple comparison test was used to compare the difference between each treatment and the control. Significance statistical analysis was performed using the GraphPad Prism 5 and recognized as significant when $p$-values were $<0.05$.

Supplementary Materials: The following are available online at http://www.mdpi.com/2072-6651/11/12/730/s1, Figure S1: Construction strategy and confirmation of the Aflste20 knockout and complemented strains.

Author Contributions: J.Y. and S.W. conceived and designed the experiments; D.L., L.Q., and Q.X. performed the experiments and analyzed the data; L.Q., Y.W. and N.L. helped to prepare the strains used in the study; D.L., J.Y. and W.S. wrote the manuscript. All authors read and approved the final manuscript.

Funding: This research was supported by the National Natural Science Foundation of China (Grant No.31600118).

Acknowledgments: We especially thank Kunlong Yang (Jiangsu Normal University) for his advice for this study. We also thank Xiangyu Bai (Pharmaceutical College of Henan University) and Guanglan Lin (Tsinghua-Berkeley Shenzhen Institute) for their kind help in related experiments, and English editing.

Conflicts of Interest: There is no potential conflict of interest declared by the authors.

\section{References}

1. Klich, M.A. Aspergillus flavus: The major producer of aflatoxin. Mol. Plant Pathol. 2010, 8, 713-722. [CrossRef] [PubMed]

2. Hedayati, M.T.; Pasqualotto, A.C.; Warn, P.A.; Bowyer, P.; Denning, D.W. Aspergillus flavus: Human pathogen, allergen and mycotoxin producer. Microbiology 2007, 153, 1677-1692. [CrossRef] [PubMed]

3. Krishnan, S.; Manavathu, E.K.; Chandrasekar, P.H. Aspergillus flavus: An emerging non-fumigatus aspergillus species of significance. Mycoses 2010, 52, 206-222. [CrossRef] [PubMed]

4. Adhikari, A.; Sen, M.M.; Gupta-Bhattacharya, S.; Chanda, S. Volumetric assessment of airborne fungi in two sections of a rural indoor dairy cattle shed. Environ. Int. 2004, 29, 1071-1078. [CrossRef]

5. Jiujiang, Y.; Cleveland, T.E.; Nierman, W.C.; Bennett, J.W. Aspergillus flavus genomics: Gateway to human and animal health, food safety, and crop resistance to diseases. Rev. Iberoam. Micol. 2005, 22, 194-202.

6. Kokalisburelle, N. Compendium of peanut diseases. J. Periodontol. 1997, 75, 1196-1202.

7. Georgianna, D.R.; Fedorova, N.D.; Burroughs, J.L.; Dolezal, A.L.; Bok, J.W.; Horowitzbrown, S.; Woloshuk, C.P.; Yu, J.J.; Keller, N.P.; Payne, G.A. Beyond aflatoxin: Four distinct expression patterns and functional roles associated with Aspergillus flavus secondary metabolism gene clusters. Mol. Plant Pathol. 2010, 11, 213-226. [CrossRef]

8. Shuguang, Z.; Monahan, B.J.; Tkacz, J.S.; Barry, S. Indole-diterpene gene cluster from Aspergillus flavus. Appl. Environ. Microbiol. 2004, 70, 6875-6883.

9. Trucksess, M.W.; Dombrink-Kurtzman, M.A.; Tournas, V.H.; White, K.D. Occurrence of aflatoxins and fumonisins in incaparina from Guatemala. Food Addit. Contam. 2002, 19, 671-675. [CrossRef] 
10. Gustin, M.C.; Albertyn, J.; Alexander, M.; Davenport, K. MAP kinase pathways in the yeast saccharomyces cerevisiae. Microbiol. Mol. Biol. Rev. 1998, 62, 1264-1300.

11. Kentaro, F.; Yukiko, H.; Tatsuya, M.; Tasuku, N.; Keietsu, A. Aspergillus nidulans HOG pathway is activated only by two-component signalling pathway in response to osmotic stress. Mol. Microbiol. 2010, 56, 1246-1261.

12. Raitt, D.C.; Posas, F.; Saito, H. Yeast Cdc42 GTPase and Ste20 PAK-like kinase regulate Sho1-dependent activation of the Hog1 MAPK pathway. EMBO J. 2000, 19, 4623. [CrossRef] [PubMed]

13. Herskowitz, I. MAP kinase pathways in yeast: For mating and more. Cell 1995, 80, 187-197. [CrossRef]

14. Levin, D.E.; Errede, B. The proliferation of MAP kinase signaling pathways in yeast. Curr. Opin. Cell Biol. 1995, 7, 197-202. [CrossRef]

15. Brewster, J.L.; de Valoir, T.; Dwyer, N.D.; Winter, E.; Gustin, M.C. An osmosensing signal transduction pathway in yeast. Science 1993, 259, 1760-1763. [CrossRef]

16. Posas, F.; Takekawa, M.; Saito, H. Signal transduction by MAP kinase cascades in budding yeast. Curr. Opin. Microbiol. 1998, 1, 175-182. [CrossRef]

17. Kosti, I.; Mandel-Gutfreund, Y.; Glaser, F.; Horwitz, B.A. Comparative analysis of fungal protein kinases and associated domains. BMC Genom. 2010, 11, 133. [CrossRef]

18. Bartholomew, C.R.; Hardy, C.F. P21-activated kinases Cla4 and Ste20 regulate vacuole inheritance in Saccharomyces cerevisiae. Eukaryot. Cell 2009, 8, 560-572. [CrossRef]

19. Josée, A.; Cunle, W.; Robert, L.; Maleek, J.; Willem, S.; Mike, O.; Thomas, D.Y.; Malcolm, W. Genetic analysis of the interface between Cdc42p and the crib domain of Ste20p in Saccharomyces cerevisiae. Genetics 2003, 163, 9.

20. Boyce, K.J.; Andrianopoulos, A. Ste20-related kinases: Effectors of signaling and morphogenesis in fungi. Trends Microbiol. 2011, 19, 400-410. [CrossRef]

21. Johnson, G.L.; Razvan, L. Mitogen-activated protein kinase pathways mediated by ERK, JNK, and p38 protein kinases. Science 2002, 298, 1911-1912. [CrossRef] [PubMed]

22. Yamada, O.; Lee, B.R.; Gomi, K.; Iimura, Y. Cloning and functional analysis of the Aspergillus oryzae conidiation regulator gene $\operatorname{brlA}$ by its disruption and misscheduled expression. J. Biosci. Bioeng. 1999, 87, 424-429. [CrossRef]

23. Park, H.S.; Yu, J.H. Genetic control of asexual sporulation in filamentous fungi. Curr. Opin. Microbiol. 2012, 15, 669-677. [CrossRef] [PubMed]

24. Horn, B.W.; Sorensen, R.B.; Lamb, M.C.; Sobolev, V.S.; Olarte, R.A.; Worthington, C.J.; Carbone, I. Sexual reproduction in Aspergillus flavus sclerotia naturally produced in corn. Phytopathology 2014, 104, 75. [CrossRef] [PubMed]

25. Jin, F.J.; Takahashi, T.; Matsushima, K.; Hara, S.; Shinohara, Y.; Maruyama, J.; Kitamoto, K.; Koyama, Y. ScIR, a basic helix-loop-helix transcription factor, regulates hyphal morphology and promotes sclerotial formation in Aspergillus oryzae. Eukaryot. Cell 2011, 10, 945-955. [CrossRef]

26. Zhang, F.; Guo, Z.; Zhong, H.; Wang, S.; Yang, W.; Liu, Y.; Wang, S. RNA-seq-based transcriptome analysis of aflatoxigenic Aspergillus flavus in response to water activity. Toxins 2014, 6, 3187-3207. [CrossRef]

27. Peter, M.; Neiman, A.M.; Park, H.O.; Van Lohuizen, M.; Herskowitz, I. Functional analysis of the interaction between the small GTP binding protein Cdc42 and the Ste20 protein kinase in yeast. EMBO J. 1996, 15, 7046. [CrossRef]

28. Lamson, R.E.; Winters, M.J.; Pryciak, P.M. Cdc42 regulation of kinase activity and signaling by the yeast p21-activated kinase Ste20. Mol. Cell. Biol. 2002, 22, 2939-2951. [CrossRef]

29. Leeuw, T.; Fourest-Lieuvin, A.; Wu, C.; Chenevert, J.; Clark, K.; Whiteway, M.; Thomas, D.Y.; Leberer, E. Pheromone response in yeast: Association of Bem1p with proteins of the MAP kinase cascade and actin. Science 1995, 270, 1210-1213. [CrossRef]

30. Smith, M.E.; Henkel, T.W.; Rollins, J.A. How many fungi make sclerotia? Fungal Ecol. 2015, 13, $211-220$. [CrossRef]

31. Valiante, V.; Macheleidt, J.; Föge, M.; Brakhage, A.A. The Aspergillus fumigatus cell wall integrity signaling pathway: Drug target, compensatory pathways, and virulence. Front. Microbiol. 2015, 6, 325. [CrossRef] [PubMed]

32. Jin, Q.; Li, C.; Li, Y.; Shang, J.; Li, D.; Chen, B.; Dong, H. Complexity of roles and regulation of the PMK1-MAPK pathway in mycelium development, conidiation and appressorium formation in Magnaporthe oryzae. Gene Expr. Patterns 2013, 13, 133-141. [CrossRef] [PubMed] 
33. Heller, J.; Ruhnke, N.; Espino, J.J.; Massaroli, M.; Collado, I.G.; Tudzynski, P. The mitogen-activated protein kinase BcSak1 of botrytis cinerea is required for pathogenic development and has broad regulatory functions beyond stress response. Mol. Plant-Microbe Interact. MPMI 2012, 25, 802. [CrossRef] [PubMed]

34. Zheng, D.; Zhang, S.; Zhou, X.; Wang, C.; Xiang, P.; Zheng, Q.; Xu, J.R. The FgHOG1 pathway regulates hyphal growth, stress responses, and plant infection in Fusarium graminearum. PLoS ONE 2012, 7, e49495. [CrossRef] [PubMed]

35. Chen, R.E.; Thorner, J. Function and regulation in MAPK signaling pathways: Lessons learned from the yeast Saccharomyces cerevisiae. Biochim. Biophys. Acta 2007, 1773, 1311-1340. [CrossRef]

36. Ana-Maria, C.; Elaine, B.; Rogers, T.R.; Mariana, C.; Mühlschlegel, F.A.; Ken, H. Candida glabrata Ste20 is involved in maintaining cell wall integrity and adaptation to hypertonic stress, and is required for wild-type levels of virulence. Yeast 2010, 21, 557-568.

37. Lee, Y.M.; Kim, E.; An, J.; Lee, Y.; Choi, E.; Choi, W.; Moon, E.; Kim, W. Dissection of the HOG pathway activated by hydrogen peroxide in Saccharomyces cerevisiae. Environ. Microbiol. 2017, 19, 584-597. [CrossRef]

38. Wu, C.; Lee, S.F.; Furmaniak-Kazmierczak, E.; Côté, G.P.; Thomas, D.Y.; Leberer, E. Activation of myosin-I by members of the Ste20p protein kinase family. J. Biol. Chem. 1996, 271, 31787. [CrossRef]

39. Leberer, E.; Ziegelbauer, K.; Schmidt, A.; Harcus, D.; Dignard, D.; Ash, J.; Johnson, L.; Thomas, D.Y. Virulence and hyphal formation of Candida albicans require the Ste20p-like protein kinase CaCla4p. Curr. Biol. 1997, 7, 539-546. [CrossRef]

40. Roze, L.V.; Laivenieks, M.; Hong, S.Y.; Wee, J.; Wong, S.S.; Vanos, B.; Awad, D.; Ehrlich, K.C.; Linz, J.E. Aflatoxin biosynthesis is a novel source of reactive oxygen species-A potential redox signal to initiate resistance to oxidative stress? Toxins 2015, 7, 1411-1430. [CrossRef]

41. Zhang, F.; Geng, L.; Huang, L.; Deng, J.; Fasoyin, O.E.; Yao, G.; Wang, S. Contribution of peroxisomal protein importer AflPex5 to development and pathogenesis in the fungus Aspergillus flavus. Curr. Genet. 2018, 64, 1335-1348. [CrossRef] [PubMed]

42. Hu, Y.; Yang, G.; Zhang, D.; Liu, Y.; Yu, L.; Lin, G.; Guo, Z.; Wang, S.; Zhuang, Z. The PHD transcription factor Rum1 regulates morphogenesis and aflatoxin biosynthesis in Aspergillus flavus. Toxins 2018, 10, 301. [CrossRef] [PubMed]

43. Yang, K.; Liang, L.; Ran, F.; Liu, Y.; Li, Z.; Lan, H.; Gao, P.; Zhuang, Z.; Zhang, F.; Nie, X. The Dmta methyl transferase contributes to Aspergillus flavus conidiation, sclerotial production, aflatoxin biosynthesis and virulence. Sci. Rep. 2016, 6, 23259. [CrossRef] [PubMed]

44. Yang, K.; Liu, Y.; Liang, L.; Li, Z.; Qin, Q.; Nie, X.; Wang, S. The high-affinity phosphodiesterase PdeH regulates development and aflatoxin biosynthesis in Aspergillus flavus. Fungal Genet. Biol. 2017, 101, 7-19. [CrossRef] [PubMed]

45. Nie, X.; Yu, S.; Qiu, M.; Wang, X.; Wang, Y.; Bai, Y.; Zhang, F.; Wang, S. Aspergillus flavus sumo contributes to fungal virulence and toxin attributes. J. Agric. Food Chem. 2016, 64, 6772. [CrossRef]

46. Livak, K.; Schmittgen, T. Analysis of relative gene expression data using real-time quantitative pcr and the $2^{-\triangle \Delta C T}$ method. Methods 2000, 25, 402-408. [CrossRef]

(C) 2019 by the authors. Licensee MDPI, Basel, Switzerland. This article is an open access article distributed under the terms and conditions of the Creative Commons Attribution (CC BY) license (http://creativecommons.org/licenses/by/4.0/). 